\section{Tentative of determination of the acidity leve in room temperature ionic liquids by electrochemical methods}

Cedric Malherbe, Thierry Robert and Bernard Gilbert* Université de Liège

Laboratoire de Chimie Analytique et Electrochimie B6C Sart-Tilman, B-4000 Liège, Belgique

Hélène Olivier-Bourbigou, Lionel Magna Institut Français du Pétrole

Division Catalyse et Séparation

CEDI « René Navarre », BP3

F- 69230 Vernaison, France

Ionic liquids have been shown as alternative solvents for a wide range of catalytic and organic reactions. ${ }^{1}$ Some of these solvents have even led to industrial applications. ${ }^{2}$

Among various properties, Brønsted acidity has been shown to play an important role in such solvents for many reactions. ${ }^{3}$ For instance, previous works report that acidic chloroaluminates containing protons may be superacids, as evidenced by the determination of their Hammett functions (down to -18) and by their use for different reactions involving acids. ${ }^{1,3-4}$ Nonchloroaluminate ionic liquids, supposedly air and moisture stable, have also been applied for acidic reactions 5 .

Considering the importance of the acidity, we have proposed a simple method for the determination of a Brønsted acidity scale in such solvents based on the determination of the Hammett acidity functions $\mathrm{H}_{0}$, using UV-Visible spectroscopy. ${ }^{6}$ The goal of this acidity scale was ultimately to find a correlation between the catalytic activities measured on acidic reactions and the solvent nature

However, we have shown that the measurement of $\mathrm{H}_{0}$, besides all the assumptions involved, is actually not truly applicable to all ionic liquids because many of them exhibit a low dissociating power and only an "apparent" $\mathrm{H}_{0}$ is measured. ${ }^{7}$ Indeed, there is more and more question of "ion pair" formation in the literature ${ }^{8-9}$ and these ion pairs will affect definitely the acidity constants of the indicators used in the Hammett procedure and in turn the $\mathrm{H}_{0}$ function.

The objective of this report was then to try to evaluate the accessible level of acidity in reference ionic liquids, namely BMImNTf, BMImOTf and $\mathrm{BMImBF}_{4}$ (where BMIm = 1-butyl3-methylimidazolium, $\mathrm{NTf}_{2}=\mathrm{N}\left(\mathrm{CF}_{3} \mathrm{SO}_{2}\right)_{2}$ and $\left.\mathrm{OTf}=\mathrm{CF}_{3} \mathrm{SO}_{3}\right)$, either starting from colorimetric indicators as we did in the past but also from electrochemical measurements. The suggested method here consists in determining a potentiometric acidity function $\left(\mathrm{R}_{0}\right)$ based on the Strehlow assumption. The basic idea is to measure the potential of the $\mathrm{H}^{+} / \mathrm{H}_{2}$ couple versus that of the Ferricinium/Ferrocene $\left(\mathrm{Fc}^{+} / \mathrm{Fc}\right)$ couple, which following Strehlow assumption, can be considered as independent of solvent. ${ }^{10}$ In practice, the higher is the measured $\mathrm{H}^{+} / \mathrm{H}_{2}$ potential, the higher is also the acidity level (then the proton activity).

In this paper, we will present the results obtained from electrochemical measurements on ionic liquids to which a given amount of strong acid (HOTf and $\mathrm{HNTf}_{2}$ ) has been added. Since the liquid containing protons exhibits a reduction wave, dynamic electrochemical methods (cyclic and differential pulse voltammetry) were first tested with the purpose of measuring the location of the reduction wave versus that of ferricinium in the same solution. These methods failed for two reasons: 1) in agreement with Silvester et $a{ }^{11}{ }^{11}$ the reduction process is not reversible on a polished platinum electrode and we found that the irreversibility increases drastically with the proton content. 2) since the medium is not buffered, the reduction process consumes locally the protons and the diffusion layer is then depleted, resulting in a variation of the local acidity. As a consequence, we think that only equilibrium measurements should be used, i. e. potentiometric measurements at zero current.

The potential of an hydrogen electrode $\mathrm{H}^{+} / \mathrm{H}_{2}$ was then measured in each ionic liquid while bubbling hydrogen gas between a large area platinized platinum electrode and a reference electrode. The amount of acid is increased gradually in the liquid and the potential is measured after each addition and stabilization. In order to avoid reduction of $\mathrm{Ag}^{+}$(commonly used in reference electrodes) by hydrogen, the reference electrode was an aluminum electrode deeping into a 57 mole $\% \mathrm{AlCl}_{3}$ $\mathrm{BMImCl}$ in a compartment separated by a glass frit. After the potential measurements, $\mathrm{Fc}$ was added to the solution and the location of the reversible $\mathrm{Fc}^{+} / \mathrm{Fc}$ system was measured in the same liquid on a glassy carbon disc (for which there is no proton wave) by differential pulse voltammetry.

Two critical experimental problems were encountered:

- as already shown, the residual impurities play a critical role on the final acidity level. Because of the high acidity level, most impurities act as bases and must be neutralized before reaching the actual acidity

- the quality of the hydrogen gas plays also a critical role on the stabilization of the potential.

Because of these experimental difficulties, the slopes of the measured potentials versus the log of the added acid amount were not the expected ones. However, at this point, conclusions can still be made:

- the $\mathrm{Fc}^{+} / \mathrm{Fc}$ couple potential was found quasi independent on the ionic liquid nature, confirming the Strehlow assumption,

- provided all the impurities are neutralized, the hydrogen electrode potential increases with the amount of added acid indicating an increase in the acidity level as expected,

- the approximate calculated values of the $\mathrm{R}_{0}$ Strehlow acidity function indicate a higher acidity level than that given by the Hammett $\mathrm{H}_{0}$ function, for all investigated acid solutions. This is in agreement with our proposition that the Hammett function leads only to a minimal acidity level, since the pKas of the used indicators are probably strongly affected by the ion pairing process.

- besides the absolute value of the acidity, the sequence of acidities measured on solutions of similar content of added acid is still $\mathrm{BF}_{4}^{-}>\mathrm{NTf}_{2}^{-}>\mathrm{OTf}$ as we have measured with the Hammett method.

Finally, it will be recalled that the acidity of proton (directly related to its chemical potential) is mainly determined by both its solvation state and its activity (concentration). All the presented results are in agreement with such proposition. Simple extrapolation from acids dissociations measured in aqueous solutions is useless since it overlooks the solvent contribution.

\section{References}

(1) Olivier-Bourbigou, H.; Magna, L., J. Mol. Cat. A., 182-183, 419 (2002).

(2) Gilbert B., Olivier-Bourbigou H. and F. Favre,

Oil \& Gas Science and Technology - Rev. IFP, 62(6), 745 (2007).

(3) Johnson K.E., Pagni R.M. and Bartmess J., Monatshefte für Chemie, 138, 1077 (2007).

(4) (a) King D., Mantz R., Osteryoung R. J. Am. Chem. Soc., 118, 11933 (1996). (b) Smith G. P., Dworkin A. S., Pagni R. M., Zingg S. P., J. Am. Chem. Soc., 111, 525 (1989).

(5) (a) Ross J., Xiao J. Green Chemistry, 4, 129 (2002); (b) Wasserscheid P., Sesing M., Korth W. Green Chemistry, 4, 134. (2002); (c) Cole A. C., Jensen J. L., Ntai I., Tran K. L. T., Weaver K. J., Forbes D. C., Davis Jr. J. H. J. Am. Chem. Soc., 124, 5962 (2002) ; (c) Fraga-Dubreuil J., Bourahla K., Rahmouni M., Bazureau J. P., Hamelin J., Catalysis Communications, 3, 185 (2002).

(6) Thomazeau C. , Olivier-Bourbigou H. , Magna L. , Luts S. and Gilbert B., J. Am. Chem. Soc., 125, 5264 (2003)

(7) Robert T., Olivier-Bourbigou H., Magna L. and Gilbert B. ECS Transactions, 3(35), 71 (2007).

(8) Fry A.J., J. Electroanal. Chem. 546, 35 (2003).

(9) D'Anna F. and Noto R., Tetrahedron, 63, 11681 (2007).

(10) Koepp H.M., Wendt H., Strehlow H. , Z. Elektrochem., 64, 483 (1960).

(11) Silvester D.S., Aldous L., Hardacre C. and Compton R.G., J. Phys. Chem. B, 111, 5000 (2007) 